\title{
SHINING A LIGHT
}

How lighting in or around sanitation facilities affects the risk of gender-based violence in camps 


\section{THE AIM OF THIS RESEARCH}

Lights in a refugee camp in Cox's Bazaar, Bangladesh. Photo: Rachel Hastie/Oxfam

Camps are places of refuge for people fleeing conflict and disaster, but they can be dangerous, especially for women and girls. In their first months, many camps rely on communal sanitation facilities - a quick and cost-effective way of meeting immediate needs and minimizing public health risks until a better solution can be developed. Sharing latrines and bathing areas with large numbers of strangers, however, can be frightening. One of the main - and unavoidable - reasons women and girls leave their shelters after dark is to go to the toilet, including to manage their menstruation, yet for many it is a risky enterprise.

In 2016, the Humanitarian Innovation Fund (HIF) set up a research challenge asking: Does lighting in or around sanitation facilities reduce the risk of gender-based violence (GBV)? During 2017 and 2018, Oxfam and researchers from the Water, Engineering and Development Centre (WEDC) at Loughborough University carried out research to try to answer this question.

The objectives of the research challenge were to identify factors that affect usage rates of sanitation facilities including those relating to dignity and privacy, as well as risks of GBV - and to assess whether, how and to what extent lighting could mitigate such risks. The research comprised a literature review, three field studies, and the compilation of eight short case studies focusing on lighting. ${ }^{1}$

Three locations were selected for the field studies: Omugo camp in Northern Uganda, Aburi camp in Damboa, NorthEast Nigeria and Hamman Al Alil 2 camp in Iraq. The studies had three stages: firstly, baseline research combined a digital survey with observations, focus group discussions (FGDs) and key informant interviews (KIIS) with residents of the camps, officials and local and international humanitarian actors. Secondly, a lighting intervention was carried out: the distribution of handheld solar lights in Nigeria, installation of fixed solar wall lights in Iraq and of solar lamp posts in Uganda. ${ }^{2}$ Finally, for the endline research, the digital survey, observations, FGDs and KIls were repeated to try to assess the impact of the light on perceptions of the risk of GBV and usage rates of sanitation facilities.

For the purposes of this challenge the research team looked at latrines and bathing shelters lor showers in the case of (raq), and any variety of portable lighting (e.g. torches or lanterns) or fixed lighting (on posts or fixed to walls/ceilings). The research team asked residents in camps about their perception of the risk of some specific forms of GBV: people looking into the facilities to watch you use them ('peeping'); sexual harassment on the way to facilities; sexual violence on the way to facilities; and sexual violence inside the facilities. These were used as indicators to measure 'fear of GBV'.

This report presents the main findings from this research. We hope that readers of this report and the associated materials will be motivated to take action to continually improve the safety of people - and especially of women and girls and those who are most vulnerable - living in camps all over the world. 


\section{RESEARCH FINDINGS}

This research concludes that good-quality lighting interventions in camps do make people feel safer. However, many factors affect safety, especially for women and girls, and lighting can only ever be part of a comprehensive and well-coordinated strategy to reduce risks of GBV.

This conclusion will not be surprising to many humanitarians. When the HIF set this challenge, it was already known that women and girls face increased and distinct safety concerns when using poorly planned communal latrines, including threats of sexual and other forms of GBV. Indeed, it was this knowledge that inspired the research challenge. ${ }^{3}$ The research confirmed these facts, but it is apparent that the extent to which women and girls have concerns about using sanitation facilities both during the day and after dark, and how many of them avoid doing so, has been underestimated. Furthermore, the extent and complex dimensions of GBV in camps have not been fully understood across all humanitarian actors.

During this research process, the digital survey provided an evidence base to support the key findings presented in this report. However, it was the discussions and interviews that brought the data to life as time and time again women and girls - and some men and boys - spoke about how unsafe they feel and the daily measures they take to navigate the multiple risks they see in their immediate environment.

Lighting is universally welcomed and increasingly recognized as a basic need for people in crisis situations; undoubtedly it makes people feel safer, and even more so when they have control over where and how it is provided. People need multiple forms of lighting - both public and household/individual lighting - but this is often provided in an ad hoc, uncoordinated manner, partly due to lack of a dedicated coordination mechanism. The research suggests that gender and other power dynamics affect access to lighting, even where there has been a blanket distribution. Females and elderly or disabled people appear to have less access, and are at greater risk of being targeted for theft. Lighting was also shown to have wider benefits - such as increasing community cohesion and the number of people in public spaces after dark which may indirectly contribute to making camps safer for their residents.

The extent to which fear of GBV affects the lives of women and girls in particular, is alarming. Many women and girls spoke of daily sexual harassment and fear of sexual assaults and rape. In Iraq, and to a lesser extent in Nigeria, social and cultural norms governing women and girls' behaviour means that simply by virtue of being female their presence in public spaces after dark is treated with suspicion, they are considered 'fair game' for harassment and assault, and held responsible if attacked. The consequences of sexual abuse or assault can be severe and even life-threatening. When the only latrines available to women and girls are communal facilities in public spaces, they manage these risks daily, and face shame and embarrassment when they can 'be seen' by men going to the latrines, especially when they are menstruating.

While the research focused on the intersections between sanitation, lighting and GBV, a high proportion of findings relate to the design, location, quality and condition of sanitation facilities and how these impact on safety. When existing quality standards such as Sphere are not met, this significantly increases fear of GBV and decreases usage. In the three field studies the location of the facilities, whether or not there was clearly signed sex segregation, and whether male and female facilities were spatially separated all impacted on usage rates and fear of GBV, with overwhelming feedback that men and women's communal sanitation facilities need to be separated. Fear of snakes and scorpions was widespread and a significant factor deterring people from using sanitation facilities, but lighting enabled people to see and avoid them.

Over the next few pages we will unpick some of these top-line findings; the case studies and field research reports from each country, which present the data and findings in greater detail, are also available. ${ }^{4}$

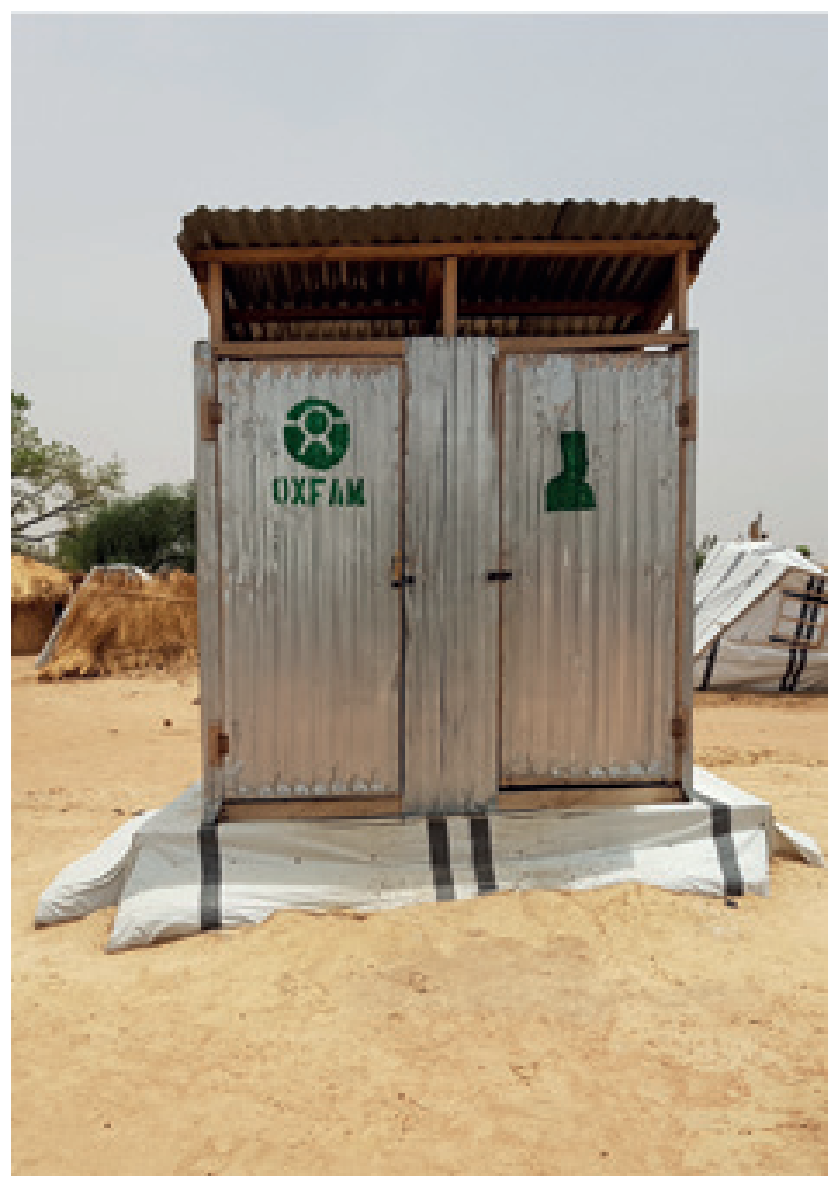

Latrines in Aburi camp in Nigeria. Photo: Marion O'Reilly/Oxfam 


\section{LIGHTING - AT SANITATION FACILITIES OR ELSEWHERE - INCREASES FEELINGS OF SAFETY BUT NEEDS TO BE PART OF A MORE COMPREHENSIVE STRATEGY TO EFFECTIVELY REDUCE THE RISK OF GBV.}

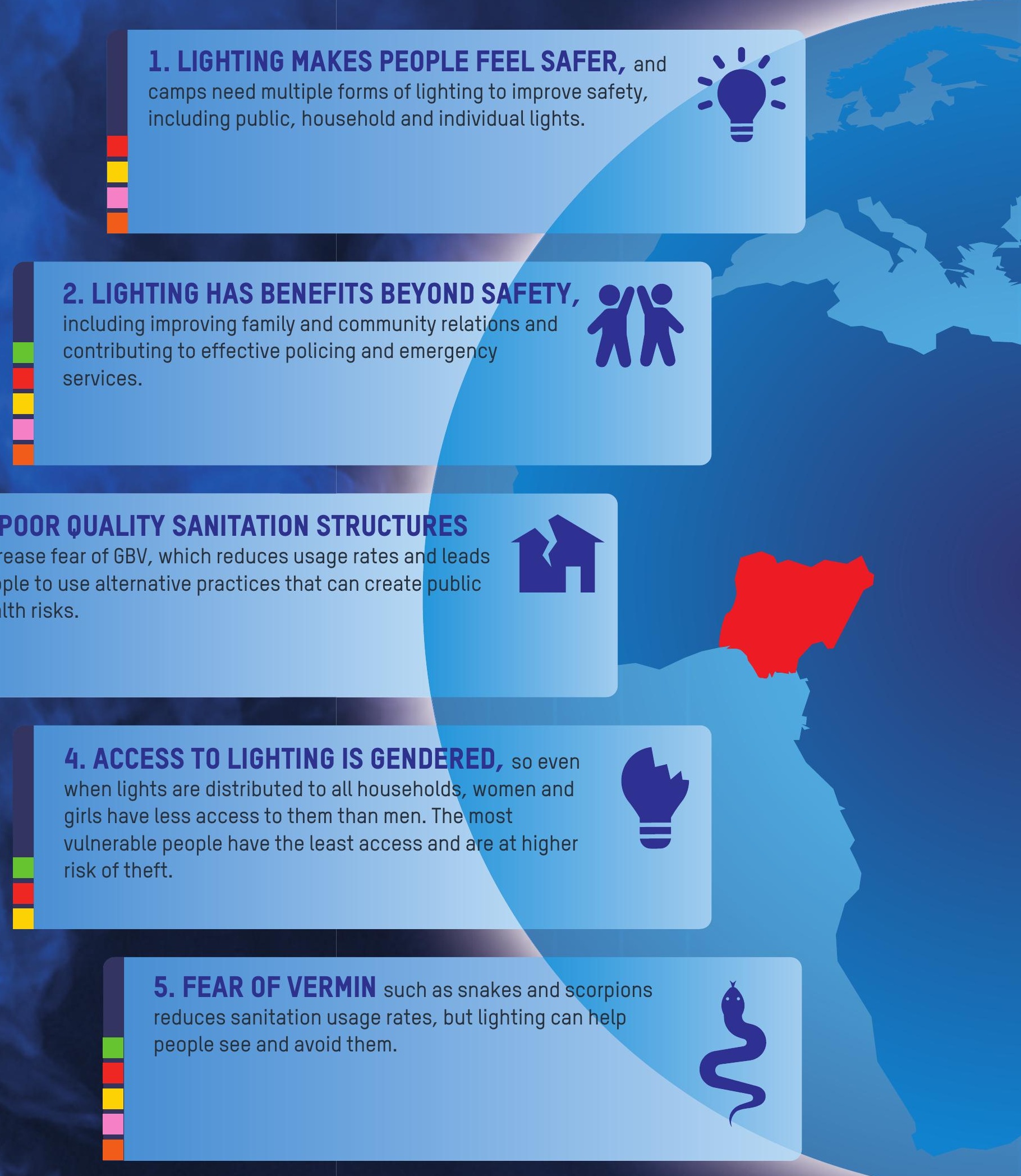




\section{KEY FINDINGS BY LOCATION}

Iraq

Literature review

Nigeria

\section{Case studies}

Uganda

6. FEAR OF GBV is high in camps, particularly amongst

women and girls, including fear of voyeuristic 'peeping',

sexual harassment and sexual violence.
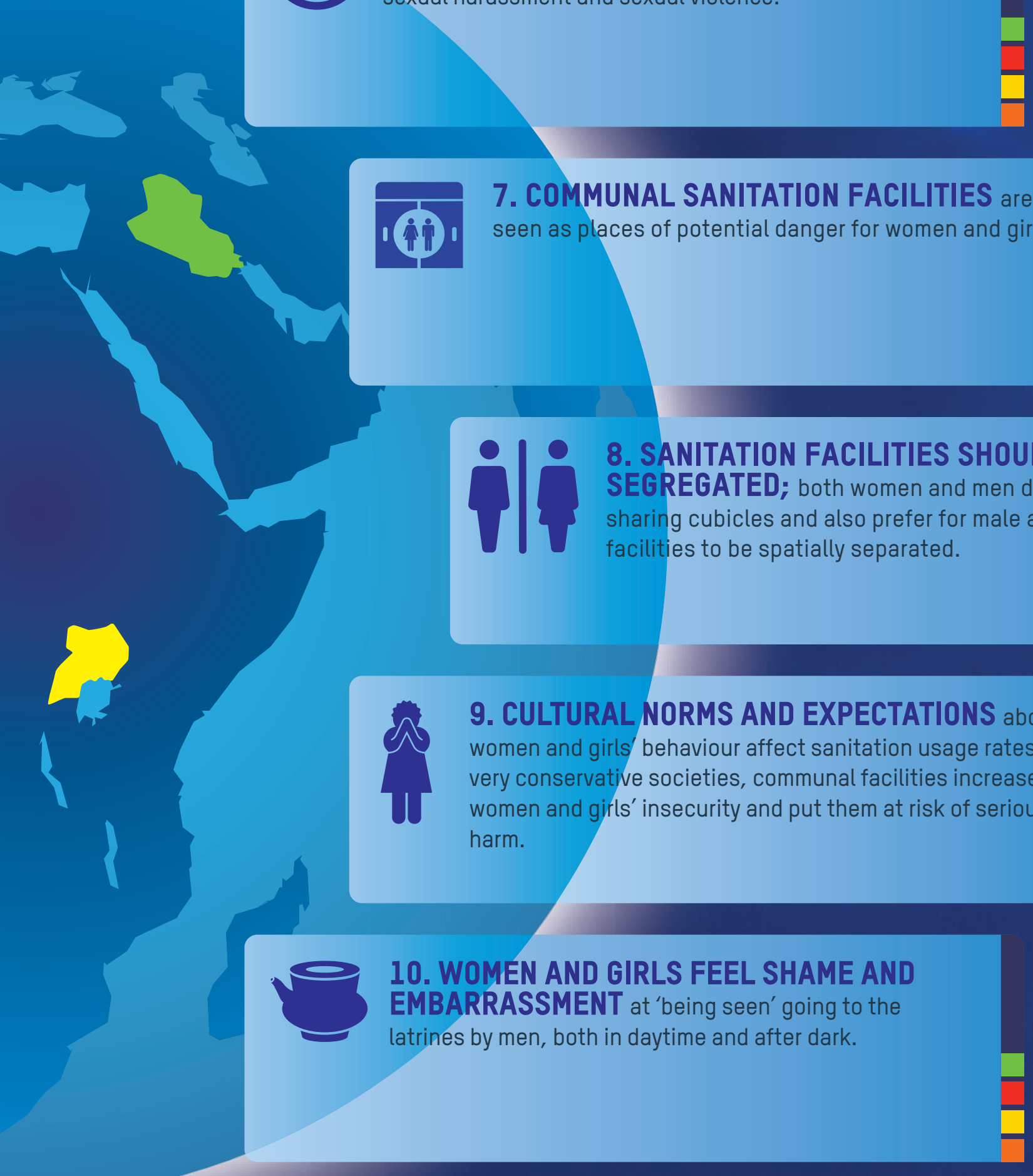


\section{Sanitation}

In humanitarian crises, the standard approach to emergency sanitation in camps is the installation of communal latrines and bathing areas, followed by a transition to neighbourhood or household facilities. In many places, the main reason women and girls leave their shelters after dark is to make an unavoidable trip to the latrine, including to manage their menstruation.

However, communal sanitation facilities are seen as places of potential danger for women and girls, especially after dark. For example, in Malakal in South Sudan, camp leaders forbade women and girls from using sanitation facilities after dark because they considered them so risky, and almost all the sources examined in the literature review highlighted the threats women and girls feel when accessing sanitation facilities. It is not only the facilities themselves that are considered risky, but also the journey that has to be made to reach them - even if the facilities are lit and safe, the pathways may present dangers. All three field studies confirmed this, and that the perceived risks are much greater in the dark.

‘During the day, the latrines are very safe, but after dark there is a real threat of being attacked. $^{\prime 5}$
So, why are communal sanitation facilities seen as so dangerous for women and girls? Location plays a big part. The safety of the location of sanitation facilities is determined by three factors: distance from people's shelters; whether sanitation facilities for males and females are spatially separated or are in a single block; and whether the facilities are sex-segregated, with clear signage.

Latrines at the edge of the camp in Nigeria were seen as dangerous because they were isolated, far from shelters, and because the camp was unfenced. In Uganda, women explained:

'Women and girls may be sexually harassed and raped if the latrines are very far from home.'

The location of male and female sanitation facilities together generated the strongest response in this research. In Iraq, women and girls who had been living for three years under strict rules that forbade them from having contact with males who were not close relatives, were faced with using latrines and showers less than a metre from facilities for men and boys. This proximity increased the likelihood of incidental contact with a male in an environment where, as one women told us, 'any contact with a man will ruin us'. ${ }^{7}$ Another interviewee explained how it could play out for a woman or girl who

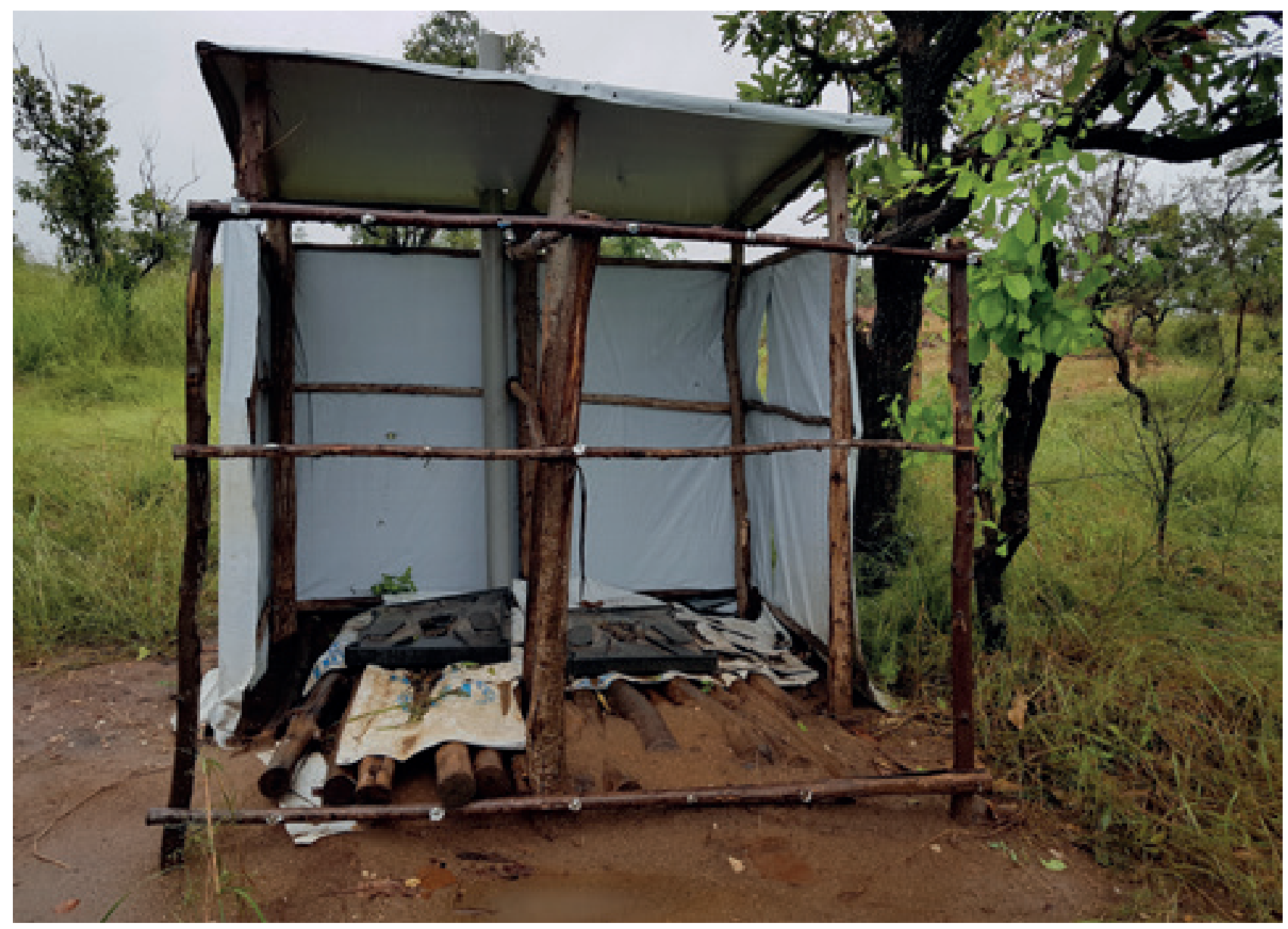

In Uganda, 92\% of female and 47\% of male respondents said they were not using the sanitation facilities after dark (baseline study, November 2017). Photo: Rachel Hastie/Oxfam 
happened to leave the latrines at the same time as a man was leaving the men's facilities:

\section{'Latrines are so close together that they} cause a massive risk for women - if seen coming out at the same time as a man, you can be labelled a prostitute. Then you are shamed and can be killed or assaulted by your family, or raped by men in the community who will say that if you tell anyone, they will say you are a prostitute.'

These are extreme examples, but the suspicions about women and girls going out after dark and the impact on their reputation was a common theme in all locations to differing extents: being seen to break societal norms relating to behaviour can stigmatize women and girls and damage their perceived 'honour' or 'reputation', with extremely serious, even life-threatening, consequences.

In general, putting communal sanitation facilities for men and women together is overwhelmingly unpopular.

Sharing the same cubicles was felt to be unacceptable by both male and female interviewees, not just in Iraq and Nigeria, but also in Uganda and in case studies from South Sudan. People repeatedly asked for segregated facilities that were clearly marked for male or female use. Many people also asked for spatial separation: i.e. a clear distance between facilities for males and facilities for females. In Uganda, where the camp is not densely populated, participants in focus groups suggested 50 metres as an appropriate distance.

The design, construction and maintenance of sanitation facilities also has a bearing on perceptions of risk of GBV. Where facilities were poor quality or temporary they often deteriorated rapidly, with plastic sheeting being stripped, walls coming apart, doors that would not close and missing locks. Poorly built and badly maintained sanitation facilities are the most dangerous for women and girls. The lack of locks, which allowed men to enter 'accidently' when women were using the facilities, was a frequently mentioned risk. Men and boys were also concerned about their privacy and people being able to watch them while they used the facilities (voyeuristic 'peeping').

In two of the research sites - Iraq and Uganda - the sanitation facilities were installed without consultation and before residents moved into the camp. Once sanitation facilities are installed it can be extremely difficult to make the changes that would make people feel safer, due to lack of resources and/or capacity. In Nigeria, the residents were consulted - initially they asked for the grass shelters they were used to, and when these proved inappropriate in the densely-populated camp, solid facilities with locking doors and concrete foundations were built and seen as far safer, showing how ongoing consultation can result in changes that improve safety.
In all the research sites, men and boys gathering socially close to the sanitation facilities was a common problem and a disincentive for women and girls to use the facilities, as well as a factor in heightened perceptions of risk of GBV. Women and girls in all locations said that they felt 'shame' and 'embarrassment' at being seen by men when going to the latrines, including for managing menstruation. This needs to be taken into account in site planning and provision of community structures, both to discourage such gatherings at sanitation facilities but also to provide alternative spaces where they can take place. Women in Iraq proposed that a full separation of facilities would be an effective way of avoiding this happening, as there would be no legitimate reason for a man or boy to be near the women's facilities. In Nigeria, community leaders had partial success in discouraging men and boys from congregating around sanitation facilities.

Sanitation facilities change over time as people establish patterns and norms of use. In Nigeria, groups of households took charge of their nearest facilities, made rotas for cleaning and had markers they understood, such as a nail, to indicate which facilities were for use by men. Women reported that they felt safer when sharing with no more than five other households, and said they had fewer concerns about sharing facilities with men from families they knew. The baseline research in Uganda took place when residents were very new in the camp and did not know each other; four months later there was a greater sense of community. Despite this, the biggest change that was expected to happen in that time did not take place -

the wholesale shift to household latrines and the decommissioning of temporary communal facilities. This research did not set out to assess the comparative safety of household, shared or communal sanitation facilities; however, in Uganda, we were able to see that female respondents using shared and household latrines expressed less fear of GBV when using sanitation facilities.

The primary rationale for humanitarians providing sanitation facilities is to reduce public health risks from unsafe disposal of faecal matter and poor hygiene. Public health risks will undoubtedly be higher if latrines are not used because they are considered unsafe, especially given the common alternatives of open defecation and use of bags/buckets in shelters without the necessary means to dispose of waste safely. Table 1 shows the number of survey respondents who said that they were not using the sanitation facilities after dark, and of those using these two alternative practices. These figures are based on self-reporting and are contextualized and further explained in the country reports, e.g. the very high figures of non-usage by males in Iraq was largely due to fears of snakes and scorpions. In Uganda, South Sudanese refugees may have practised open defecation in their villages, whereas many of the camp residents in Iraq would have had bathrooms in their homes. Significant 


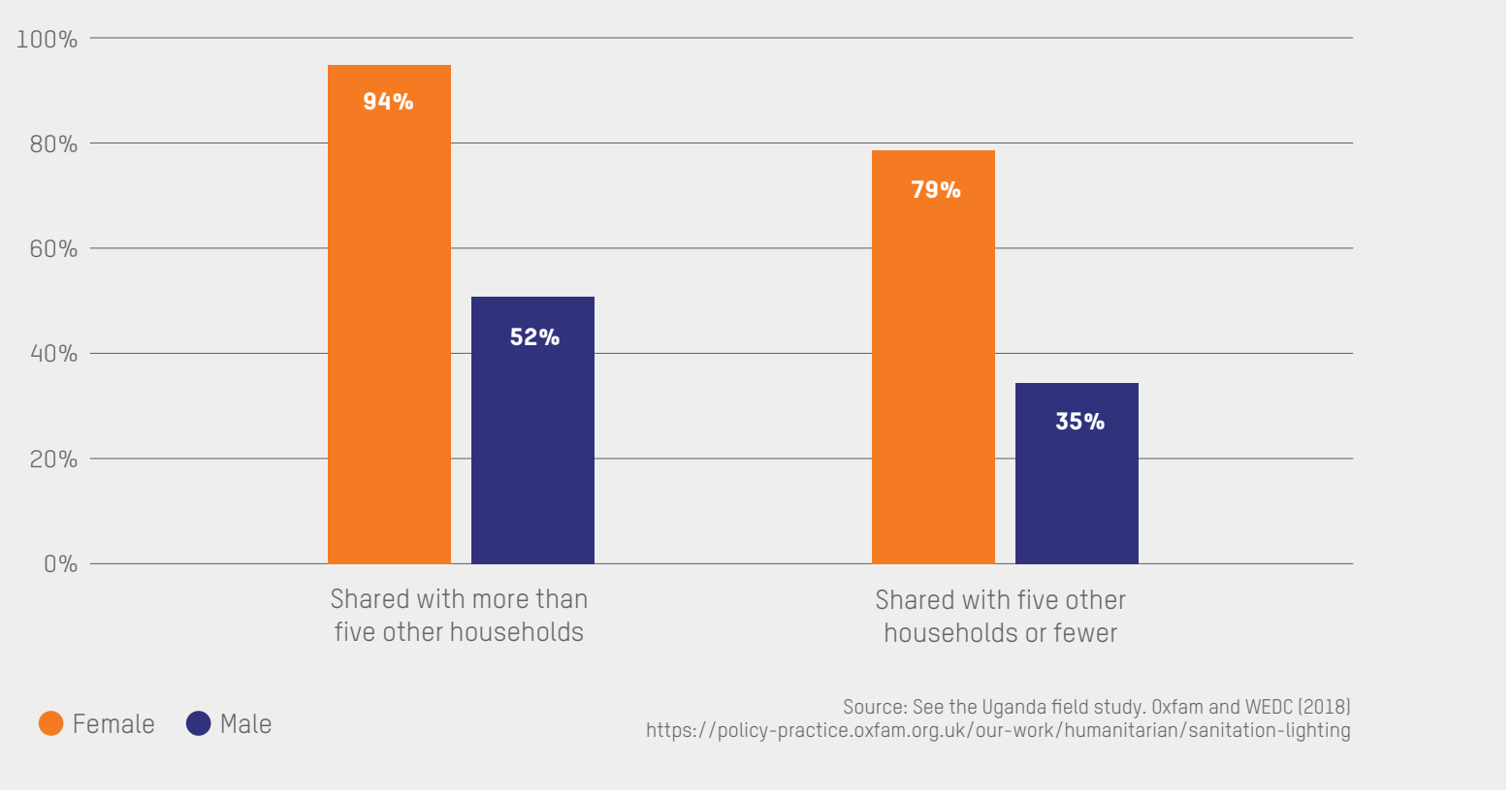

numbers of men in Iraq and Uganda preferred not to say what they do if they don't use the sanitation facilities.

The use of container-based sanitation using bags or buckets within shelters is common, especially for women in Nigeria and both men and women in Uganda, although no provision was made in the humanitarian response to allow for the safe disposal of waste. Refugees in Uganda reported that they threw waste into the bush and washed out containers at water points, and the research team observed contamination at water points that was consistent with this practice.

Substandard toilets may present a cheap solution in the short term, but once repair, maintenance and replacement costs are factored in they are likely to be more expensive in the long term. Women and girls already see communal sanitation facilities as potentially dangerous. Poorly constructed and maintained facilities are likely to put them at even greater risk of sexual harassment, assault and violence.

The humanitarian sector has well-established standards, notably the Sphere standards, which are not being met consistently in the case of emergency sanitation. There is an urgent need to ensure that humanitarian actors meet existing quality standards in sanitation - not only for public health reasons, but also as an important part of a GBV reduction strategy.

TABLE 1: ALTERNATIVE SANITATION PRACTICES OF RESPONDENTS NOT USING FACILITIES AFTER DARK IN THE THREE STUDY LOCATIONS (BASELINE)

\begin{tabular}{|c|c|c|c|c|c|c|}
\hline & \multicolumn{6}{|c|}{ Self-reported use of bags/buckets and open defecation after dark } \\
\hline & \multicolumn{3}{|c|}{ Female respondents } & \multicolumn{3}{|c|}{ Male respondents } \\
\hline & $\begin{array}{l}\% \text { not using } \\
\text { sanitation } \\
\text { facilities }\end{array}$ & $\begin{array}{l}\text { \% using bags / } \\
\text { buckets in } \\
\text { shelter }\end{array}$ & $\begin{array}{l}\text { \% using } \\
\text { open } \\
\text { defecation }\end{array}$ & $\begin{array}{l}\% \text { not using } \\
\text { sanitation } \\
\text { facilities }\end{array}$ & $\begin{array}{l}\text { \% using bags/ } \\
\text { buckets in } \\
\text { shelter }\end{array}$ & $\begin{array}{l}\text { \% using } \\
\text { open } \\
\text { defecation }\end{array}$ \\
\hline $\begin{array}{l}\text { Iraq } \\
\text { (17\% of male } \\
\text { respondents } \\
\text { preferred not to say) }\end{array}$ & $63 \%$ & $1 \%$ & $3 \%$ & $84 \%$ & $0 \%$ & $15 \%$ \\
\hline $\begin{array}{l}\text { Uganda } \\
\text { (10\% of male } \\
\text { respondents } \\
\text { preferred not to say) }\end{array}$ & $92 \%$ & $46 \%$ & $49 \%$ & $47 \%$ & $30 \%$ & $16 \%$ \\
\hline $\begin{array}{l}\text { Nigeria } \\
\text { (2\% of male and } \\
\text { female respondents } \\
\text { preferred not to say) }\end{array}$ & $44 \%$ & $24 \%$ & $9 \%$ & $48 \%$ & $15 \%$ & $18 \%$ \\
\hline
\end{tabular}

Note: Figures are percentages of total female or male respondents in each location during baseline research. 


\section{'Women should have a} different latrine from men and they should be at least

40-50m apart'

FGD with young male refugees, Uganda
If we separate the latrines, then it is clear if a man is hanging around for a bad purpose'
'Providing lights inside and outside the latrine would make us feel safer FGD with young men, Nigeria
We do use the latrines that are made of cement, have locks, and are well covered and durable

\section{INCREASES USAGE RATES}

\section{PRIVACY}

significantly affects usage rates. Women and girls' usage in

particular increases when

structures are solid and internal locks are functional.

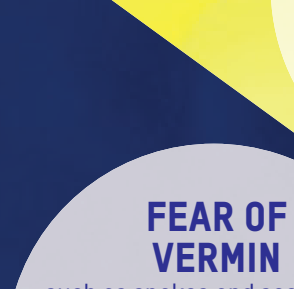

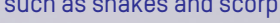
high, but lighting can help people see and avoid them.
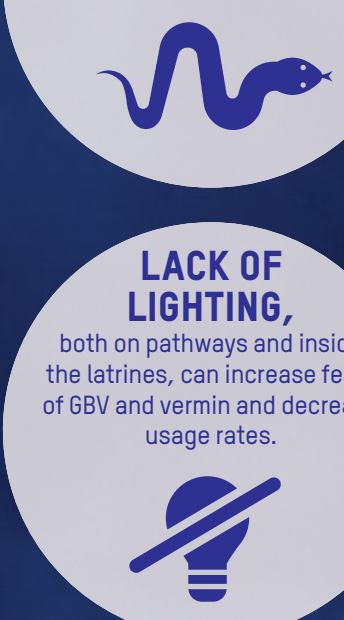

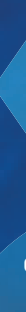

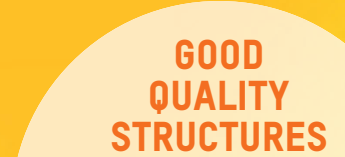

make people feel safe. Strong walls

and well maintained facilities increase usage rates.

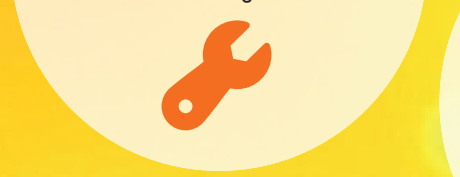

\section{LIGHTING,}

both on the pathways to and from sanitation facilities and inside them, can reduce the fear of GBV and increase usage.

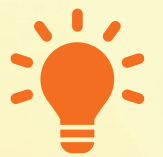




\section{Protection and gender-based violence}

Gender-based violence (GBV) is always taking place, regardless of whether it can be seen or people are talking about it. In fact, it is very unlikely that people will talk about it due to stigma and the consequences of doing so, including that survivors are blamed for attacks. A GBV specialist in Iraq confirmed that 'Women don't usually talk about sexual violence ${ }^{\prime 9}$ and Oxfam's Protection Team in Uganda confirmed that 'It's very difficult to get information from people about sexual violence in the camps. ${ }^{10}$ During an assessment in Nigeria, camp residents explained that they did not formally report cases of sexual violence; instead, a girl might be expected to marry the perpetrator, or a settlement might be agreed between the parties. ${ }^{11}$ Therefore this research, in line with best practices and ethical standards, is not based on formally reported incidents of GBV but on perceptions of risk and fear of GBV.

\section{'If something happens to a woman she should} be blamed because she didn't listen to advice. ${ }^{12}$

GBV is driven by long-standing and deeply rooted gender inequalities that determine the role and expectations of women and girls as well as men and boys. This was evident during the field research: societal norms governing women and girls' behaviour, especially in public spaces, create a hostile and dangerous environment when they have no choice but to use communal sanitation facilities. In all three field research sites, people in the camps were fleeing conflict. It is well known that GBV often increases in conflict as a deliberate tactic by armed actors, but also due to the general insecurity and upheaval that may break down the usual social norms and protections within a community.

Researching issues related to GBV must be done carefully and in line with strict ethical guidelines Isee methodology for full details). During this research, no one was directly asked about any personal experience of GBV. Instead they were asked in the survey to rate how worried they were about 10 risks related to using sanitation facilities, which included 'vermin such as snakes and scorpions', 'physical hazards like uneven ground', and four risks which were used as indicators for fear of GBV:

- People watching while you use the facilities ('peeping')

- Sexual harassment on the way to the latrines

- Sexual violence when using the latrines

- Sexual violence inside the latrines.

Levels of 'fear of GBV' were calculated by the number of survey respondents who said they were 'very worried' about at least one of these indicators. Levels of fear of GBV among women and girls in camps were alarmingly high in all locations.

In Iraq, there were far higher levels of fear of GBV among female than male respondents, although these had reduced significantly by the endline. Girls aged 16-19 registered the highest levels of fear, followed by women aged 20-25. 'Peeping' was the greatest concern for women, both in the day and after dark. This was backed up by FGDs and KIls, where people raised concerns about being watched or recorded on smartphones held through broken windows in latrines and showers; this could lead to allegations of prostitution, blackmail and serious reputational damage that could result in violence, stigmatization and sometimes even death. Even though the installation of lighting at the sanitation facilities was welcomed and had a positive impact on perceptions of safety, the location of female sanitation facilities less than a metre from those for males was identified as the most significant risk factor, combined with a generally hostile environment for women and girls. It should be noted that the risk of 'being seen on the pathway to the sanitation facilities' was not one of the four indicators for GBV, although it is closely related to the social and cultural issues around women and girl's behaviour in public. At endline, out of 107 female survey respondents, 70 women and girls cited the risk of 'being seen' as a factor that prevented them using the sanitation facilities after dark. By comparison, male respondents reported very little fear of GBV. However, it is noteworthy that four males (from a total of 100 male respondents) did report a fear of sexual violence in the facilities after dark in the endline data; and while this research did not include boys aged under 16, one key informant highlighted that:

TABLE 2: LEVELS OF FEAR OF GBV AT BASELINE AND ENDLINE IN THE THREE STUDY LOCATIONS

\begin{tabular}{|c|c|c|c|c|}
\hline & \multicolumn{4}{|c|}{ Levels of fear of GBV } \\
\hline & \multicolumn{2}{|c|}{ Female respondents } & \multicolumn{2}{|c|}{ Male respondents } \\
\hline & Baseline & Endline & Baseline & Endline \\
\hline Iraq & $50 \%$ & $19 \%$ & $2 \%$ & $5 \%$ \\
\hline Uganda & $95 \%$ & $85 \%$ & $38 \%$ & $40 \%$ \\
\hline Nigeria & $55 \%$ & $58 \%$ & $46 \%$ & $11 \%$ \\
\hline
\end{tabular}

Note: The country research reports present this data in far greater detail. See: https://policy-practice.oxfam.org.uk/our-work/humanitarian/sanitation-lighting 
'Boys are also being raped, but this is rarely discussed openly. ${ }^{\prime 13}$

In Uganda, the levels of fear of GBV were extremely high among female respondents: $95 \%$ during the baseline, and $85 \%$ at endline. The pattern across age groups is fairly even, although girls aged $16-19$ registered the highest levels of fear, followed by women aged 20-25. At baseline and endline, female respondents reported high levels of fear across all four GBV indicators during the day, with 'peeping' recording the highest levels. Even higher levels of fear were reported across all risks after dark. Male respondents also had high levels of fear of GBV, largely of 'peeping', although five out of 80 male respondents at endline reported a fear of sexual violence on the way to the sanitation facilities after dark. GBV experts confirmed that many of the refugees would have experienced or been exposed to sexual violence while fleeing South Sudan,,$^{14}$ and although people are always reluctant to speak about GBV, this was less the case here than in the more conservative communities in Nigeria and Iraq. The refugees had only recently arrived at the time of the baseline and many sanitation facilities lacked doors, locks or even walls, offering little privacy or safety. This explains the high levels of concern about 'peeping', but not the levels of fear of other forms of GBV that were also very high. That fear of GBV remained so high among females at endline (85\%) is alarming and indicates a need for urgent action to address why so many females feel unsafe in the camp.

In Nigeria, more than half of the female respondents recorded a fear of GBV, with a slight increase at endline
(168 out of 289 female respondents). Girls aged 16-19 reported the highest levels of fear $(73 \%$ at baseline and $84 \%$ at endline). High levels of fear of GBV were also reported by men at baseline, although this had improved significantly by endline. The reduction in fear of GBV among male respondents may be partly explained by the increase in sample size from 54 at baseline to 178 at endline. During the endline research, 19 men expressed a fear of GBV, evenly spread across all four GBV indicators, and the research team were told of an alleged incident in which a man was raped while collecting firewood.

The differences in perceptions of safety and risk are clearly gendered and intersect with other factors such as age - with adolescent girls having very high fears of GBV - and aspects of identity, for example, widows in Iraq were perceived to have had links to Isis and therefore faced hostility from the community and authorities. In all locations women and girls face some level of suspicion when they go out in public spaces after dark. Women have to ask permission from male family members to go to the latrine after dark, and often they have to be escorted. In Nigeria, lighting removed the need to be escorted for some teenage girls, but not for all; and in Iraq, even with the lighting women had to be escorted. The need for females to be escorted created problems for men and boys in the highly militarized locations in Iraq and Nigeria, due to suspicion regarding any potential links to nonstate armed actors. This reportedly put men and boys at risk of arrest or detention, and may also have been a trigger for intimate partner violence. In all locations, reference was also made to men and boys being raped and sexually assaulted.

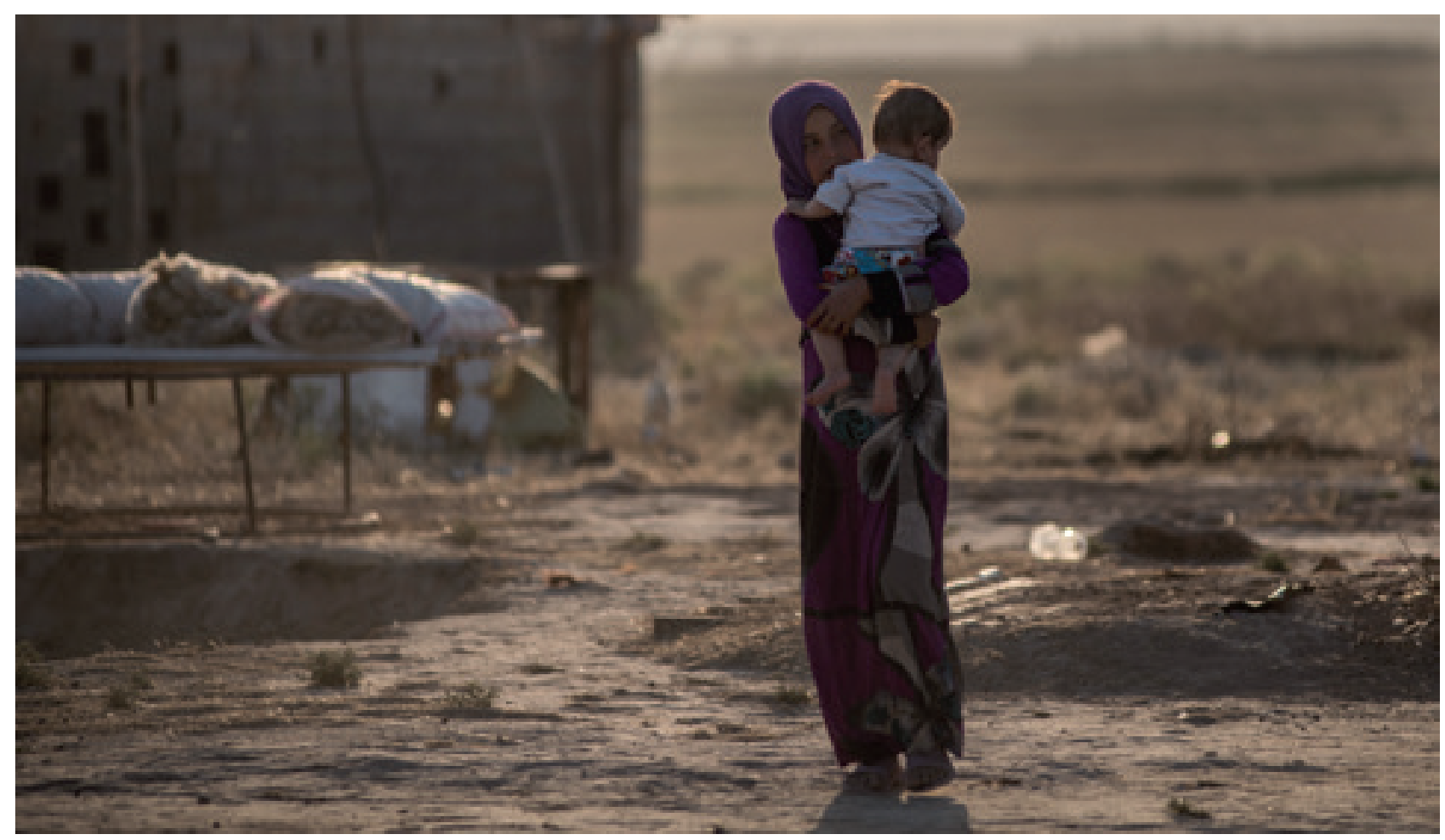

A girl carrying a child through a refugee camp in Iraq. Photo: Tommy Trenchard/Oxfam 
When asked what would make people feel safer using the sanitation facilities after dark, answers were very context-specific but also practical, and suggestions could very easily be implemented by humanitarians and camp authorities. In Nigeria at baseline there was a strong emphasis on lighting, but also location and greater distance between male and female communal facilities. By endline, after lights had been distributed to all households, the emphasis shifted towards build quality and maintenance, including the need for strong walls, doors and locks. Perhaps this was because facilities were by then suffering from wear and tear, although the shift from grass to concrete structures had increased feelings of safety. Some $89 \%$ of female respondents said that locks would make them feel safer after dark.

Ugandan male and female respondents overwhelmingly asked for lighting inside and outside the facilities, better locations, and stronger doors and walls, at both baseline and endline. Unfortunately, it had not been possible to install latrine lighting during the research, although if the transition to stronger household or shared facilities can be accelerated this may be possible.

During the baseline in Iraq, lighting was also a top request among male and female respondents, who also asked for better location of and greater distance between male and female facilities. By endline, after Oxfam had affixed lights outside sanitation facilities, priorities shifted to stronger walls, doors and locks, with the continued request for greater distance between male and female facilities. While requests from male and female respondents followed fairly similar patterns to those in the other study locations, it is noticeable that in Iraq male and female respondents prioritized quite differently from each other, perhaps an indication of how differently they experience their environment.

The results of this research as they relate to GBV are not surprising, but they are important in evidencing what needs to be done to reduce risks of GBV in camps.

Awareness of these risks varies: a camp official in Nigeria said he had never heard of any cases of sexual assault or violence; this was in stark contrast to the perspective of a local NGO staff member, who estimated hearing of 50-60 cases a month across all the camps in Damboa, including cases from Aburi. Indeed, initial presentations of these research findings showed that many of the risks that women and girls face are poorly understood by humanitarians who do not specifically work on GBV issues. In fact, discussions during the field research indicated that some humanitarians are resistant to accepting that GBV is taking place, persistently downplay its impact and, despite best practice guidance to the contrary, are unwilling to take action without 'hard evidence'. This is a serious hindrance to effective, coordinated and comprehensive action to reduce risks of GBV in camps.

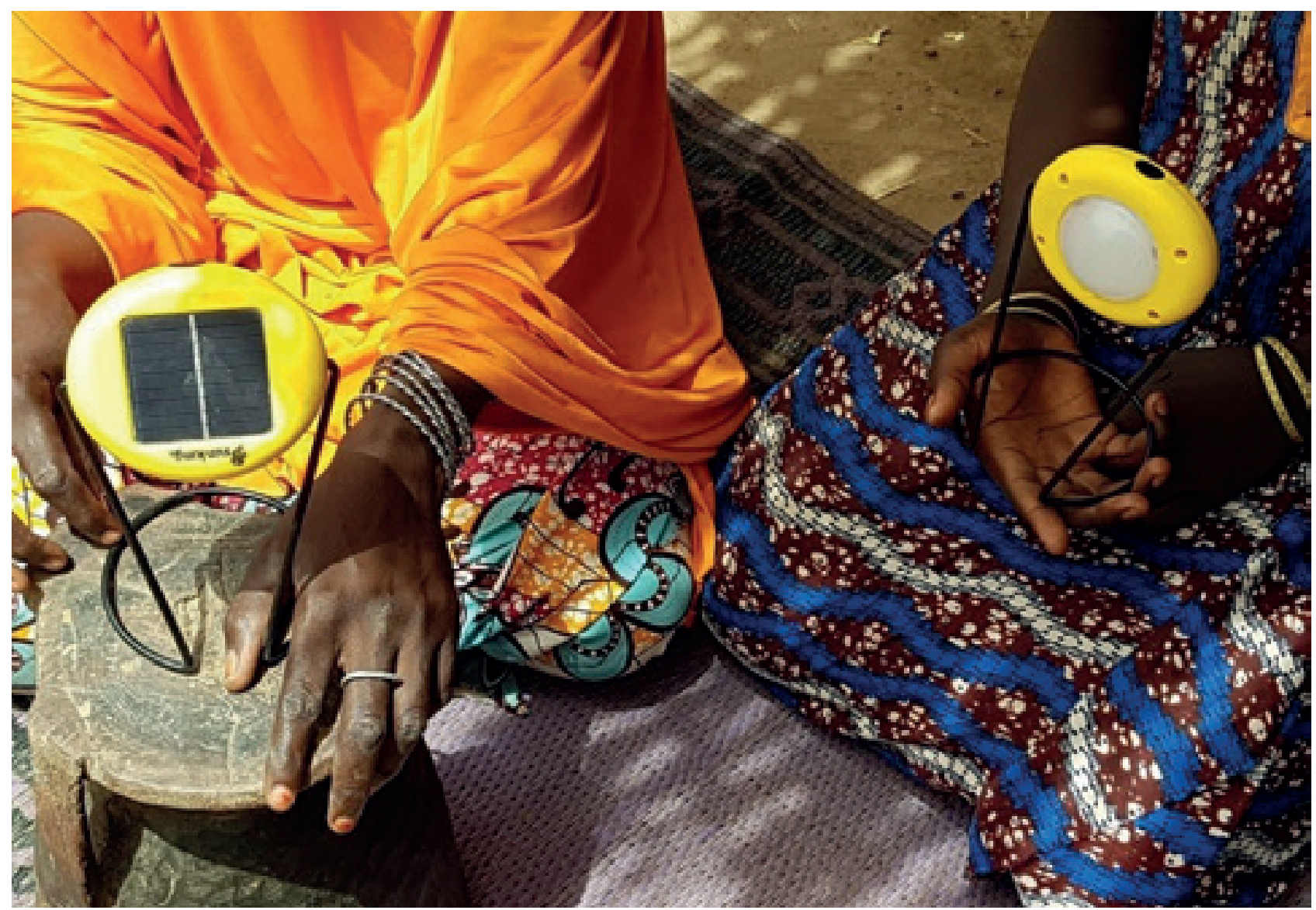

Handheld lights distributed in Aburi camp, Nigeria. Photo: Marion O'Reilly/Oxfam 


\section{GBV IS HAPPENING EVERYWHERE BUT IS UNDER-REPORTED WORLDWIDE.}

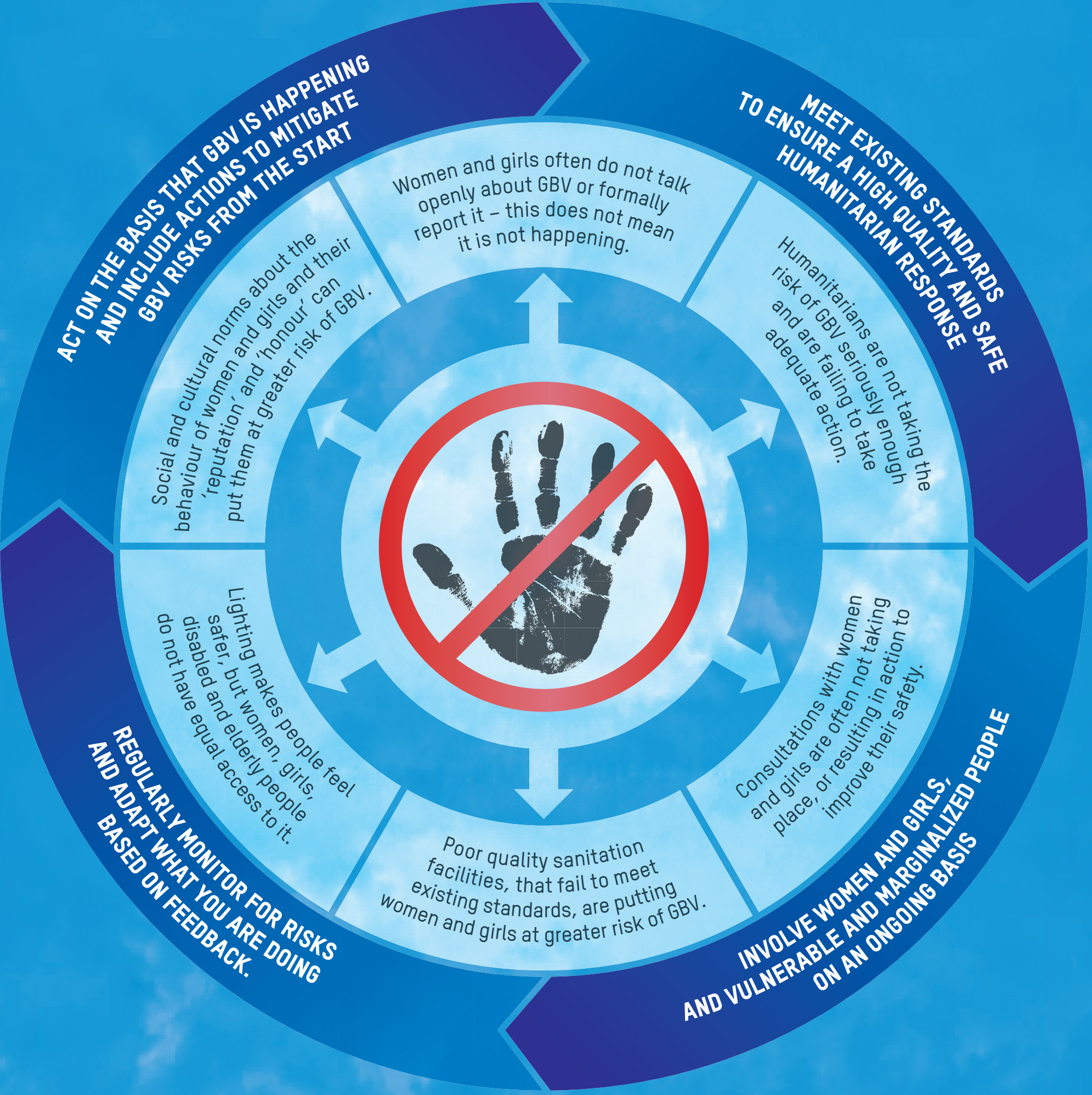

\section{IN CAMPS, WOMEN AND GIRLS' FEAR OF GBV IS WORRYINGLY HIGH.}




\section{Lighting}

The desire for lighting in camps is clear, and it plays a major role in how safe people perceive their environment to be. Oxfam distributed or installed lighting in the three field locations as part of this research: solar lamp posts in Uganda, solar wall lights at sanitation facilities in Iraq, and handheld solar lamps in Nigeria. Although it is impossible to measure the impact lighting has on reducing fear of GBV given the multiple other factors at play, it is clear that lighting does make people feel safer and can reduce risks of GBV when strategically combined with other measures. Lighting in camps is appreciated, welcomed and even demanded as a basic need. When asked what would make them feel safer using sanitation facilities after dark, people repeatedly asked for lighting on pathways, in and outside facilities, and throughout the camp. In Nigeria, after the solar lamps had been distributed, perceptions of risks after dark reduced and young women reported that they were 'not afraid to use the latrines after dark because of the light' ${ }^{\prime}$ with young men saying that 'using the light makes us safe'. ${ }^{16}$ In Iraq, participants in a FGD for women with disabilities told us:

\section{'Now there's lighting around the sanitation facilities, it's good and people do feel safer.'}

However, at the end of the research there were still many requests for more lighting in all areas of the camp, additional portable devices for individuals and larger households, and lighting inside and outside the latrines.

People need multiple forms of lighting and camps need comprehensive, coordinated lighting strategies including public, household and individual lighting; general 'ambient' light; directional light for specific tasks or walking around after dark; and lighting at facilities such as latrines, markets, medical clinics and the pathways that lead to them.

\section{However, badly done lighting can put people at greater} risk. Simply adding lighting to badly located and poorquality sanitation facilities will not make people any safer. The case study from Malakal camp in South Sudan, where lighting at latrines resulted in men congregating there and leaders banning women from using the facilities after dark, illustrates how poorly designed light can create greater risks. A minority of interviewees suggested that lighting can make vulnerable individuals more visible, and therefore increase their risk of being targeted for theft or assault. Managing such risks, however, is not impossible. Portable lighting that individuals were able to control themselves was particularly appreciated, and community-based approaches can ensure lighting is appropriate and effective for all. The case study on community lighting from Bangladesh shows how consultations with women led to lamp posts being angled so as not to shine directly on sanitation facilities, to avoid making users too visible in a culture where women feel embarrassed at being seen there. The Greece case study shows how ongoing consultations in Doliana enabled continual adaptation and improvement in lighting.

The literature review showed how public lighting (such as lamp posts) is vulnerable to theft and vandalism, and can lead to anti-social behaviour. Community-based approaches may be able to minimize such risks, and Maintenance Groups such as those highlighted in the Bangladesh case study can help care for and maintain public lights while monitoring performance and identifying problems such as light pollution into shelters. Camp residents often have skills and capacity to contribute - as is demonstrated by the Lebanon case study, where Syrian refugees were able to participate in selecting the model of light and also used their skills as electricians to install the lighting system. The community agreements they made on fuel payments will enable greater sustainability, and this approach was clearly highly valued by the refugees, who spoke of their appreciation for being treated with dignity and respect.

People in all of the camps in this study had some form of lighting already: be it the lamp posts in Iraq, solar lights distributed by aid agencies, battery torches from local markets, mobile phone lights or rechargeable le.g. wind-up) lights, while some people were using kerosene lamps, candles or lit grass or sticks. The continued reliance on battery torches is marked, especially among men and even after solar lights were distributed. Goodquality solar lighting is highly appreciated as a safe form of free energy. The case study from Panyijar in South Sudan shows how solar lighting can improve safety, as the conflict makes accessing markets to buy batteries dangerous, and prices fluctuate significantly. In addition, the fire risks of candles, sticks and kerosene was raised in all field studies. Experience from Bangladesh illustrates that the quality of household solar devices and their benefits to users vary hugely, but it also shows how effective coordination and jointly agreed technical guidance can drive up standards and promote a gendersensitive community-based approach.

\section{Access to lighting is affected by gender and power}

dynamics in households and communities. Consultation with all members of a community, for example in determining which public locations should be lit and how, is essential to ensure that the most marginalized and vulnerable people's safety needs are met. Even when lights are distributed to all households, men and older boys have greater access to lighting than women and girls. When people are sharing any resource, some will get priority over others. A key informant at the Office of the Prime Minister in Uganda explained that:

'People like the lights, but households are given just one, even if they have ten people across three shelters.' 
Survey results which showed that men had more access to lights than women and girls prompted the distribution of two solar lights to each Rohingya household in the camps in Bangladesh. This appears to have given women and girls greater access, although some of the lights did appear in local markets for resale.

Lighting is a relatively new field for humanitarian actors and little technical guidance exists. This results in mistakes in installation, including misalignment of solar panels and incorrect positioning of structures. There is also a lack of guidance on safety issues, such as how to ensure structures are storm-resistant and safe ways to clean solar panels. Planning for sustainability in public lighting is a critical gap, and any efforts to fill it are thwarted by short donor funding cycles in emergency responses. Public lighting is extremely expensive to provide and should last 10-20 years, but much of that expenditure will be wasted if structures are not maintained. There is an opportunity to establish multisectoral coordination structures and to develop holistic technical guidance combining social, cultural and technical issues.

Investments in lighting have benefits beyond safety. Light enables people to use sanitation facilities more easily, keep them cleaner and avoid stepping into waste, and helps women and girls use menstrual hygiene products. Interviewees spoke of the difference lighting makes to their interactions as a family and community, how it lengthens the day, enables people to study and markets to thrive. In Uganda, it made ambulance services more effective and helped community policing. While the rationale for and design of lighting initiatives must be primarily driven by safety concerns, it is a cost-effective way to make a much wider positive impact on people's lives, with considerable scope for new and innovative approaches. These could include market approaches using cash and vouchers for household lighting, using areas under lamp posts as community spaces, or renting the space to traders to generate income for spare parts and repairs.

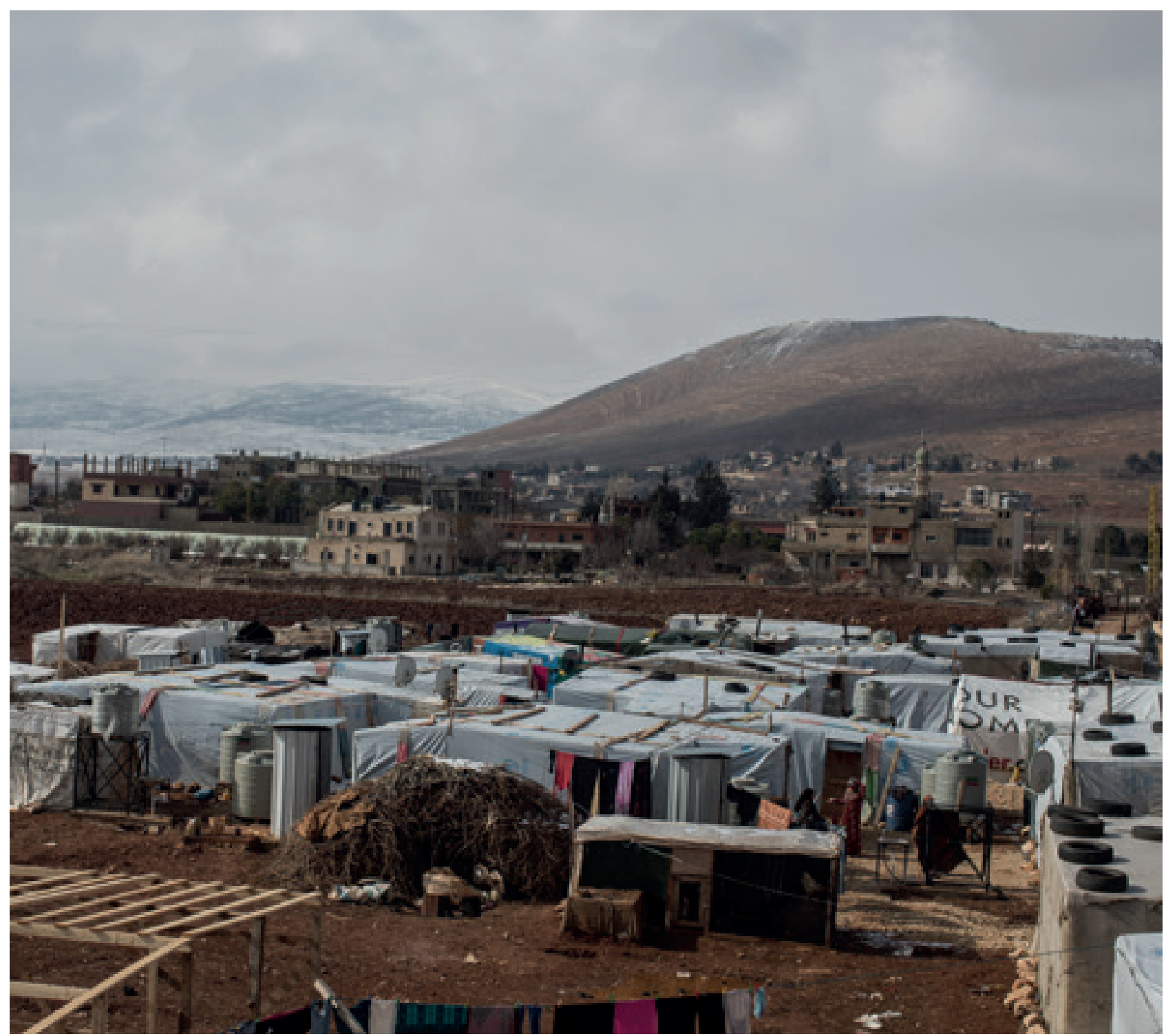

An informal settlement for Syrian refugees in Lebanon. Photo: Sam Tarling/Oxfam 


\section{PUBLIC LIGHTING}

\section{OPTIONS \\ CAN COVER:}

- the whole camp

- the main pathways and junctions

- inside and outside key services

(e.g. medical centre)

- inside and outside

communal/neighbourhood

facilities (e.g. latrines)

\section{TOP TIP!}

Ensure that all lights - public or household - have warranties that both you and the community can activate if necessary.

\section{LIGHTS CAN BE:}

- multidirectional for general ambient lighting

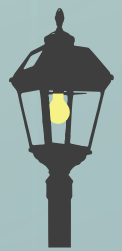

- unidirectional for lighting a specific area

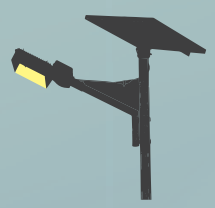

- wall or ceiling lights on the interior or exterior of buildings or structures

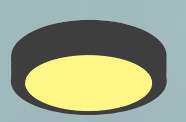

\section{BRIGHT} IDEAS:

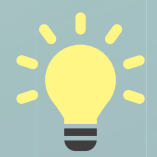

Public lighting should be positioned and angled to correctly illuminate the target area and avoid causing light pollution in shelters.

Public lighting must be:

- based on sustainable energy

- cyclone/storm proof

- vandal/theft proof

- waterproof

- easily maintained by local people - easy to find spare parts for

- strings of lights

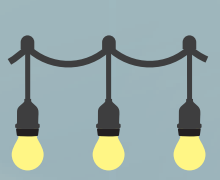

\section{PEOPLE NEED MULTIPLE}

\section{HOUSEHOLD AND INDIVIDUAL LIGHTING}

\section{ACCESS TO AND CONTROL OVER LIGHTING IS GENDERED}

Women and girls often have less access to lighting than men and boys, even when lights are distributed to all households.

Community power dynamics mean the most marginalized and vulnerable people often have less access to light and are more vulnerable to theft.

Assessments, consultations and community-based initiatives need to take measures to ensure the equal inclusion of all members of the community, including women and girls, elderly and disabled people, and sexual and gender minorities.
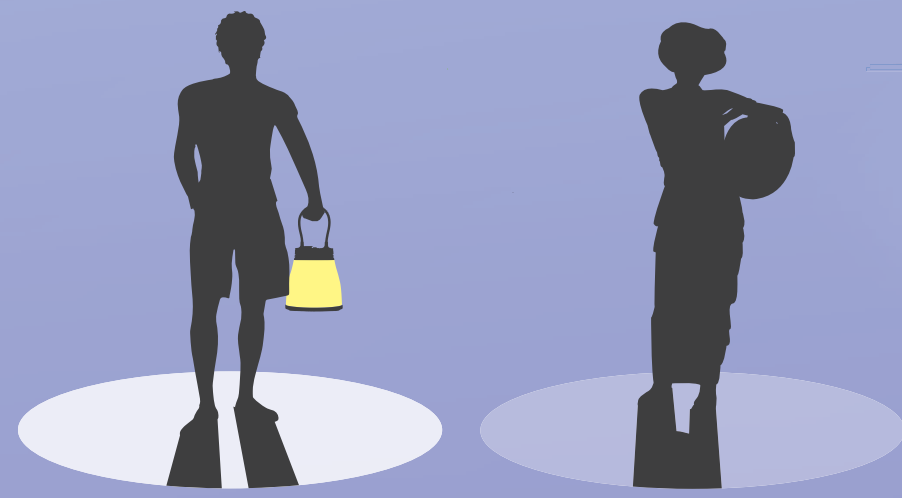

\section{PORTABLE OPTIONS}

Lanterns or lamps can be hung up to light a shelter and give general ambient light, or used on high power for specific tasks (e.g. reading or cookingl. They should be robust, water resistant and have energy-saving settings. Integrated mobile phone chargers are popular.

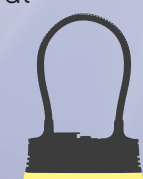

Torches should be light and portable with a directional beam to facilitate movement. Hands-free is useful; and the ability to be hung up, energy-saving settings, water resistance/waterproofing and integrated phone chargers are popular. 


\section{CAMPS NEED A COMPREHENSIVE LIGHTING STRATEGY}

1. Prioritize lighting for the safety of the most vulnerable people.
2. During the first phase, a blanket distribution may be required but this should swiftly shift to a more participatory community-based approach.
6. Purchasing locally can boost the economy and reduce tensions with the host communities, but make sure that quality and safety standards are met.

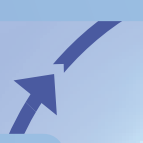

5. Prioritize low cost, renewable and sustainable energy sources.
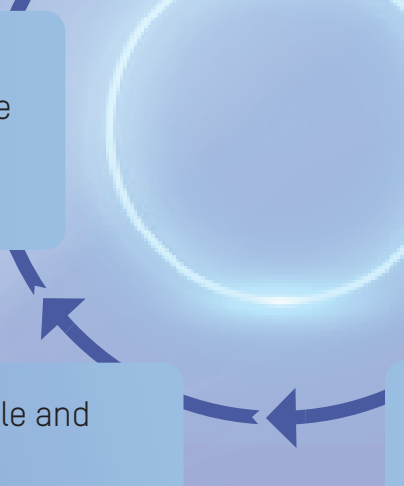

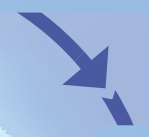

3. Involve camp management, site planning, protection, shelter and GBV actors, and a range of community representatives.

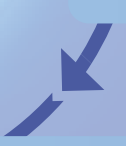

4. Agree joint technical standards to ensure adequate coverage and consistent quality.

\section{FORMS OF LIGHTING}

\section{COMMUNITY-BASED LIGHTING IS MORE EFFECTIVE AND SUSTAINABLE}

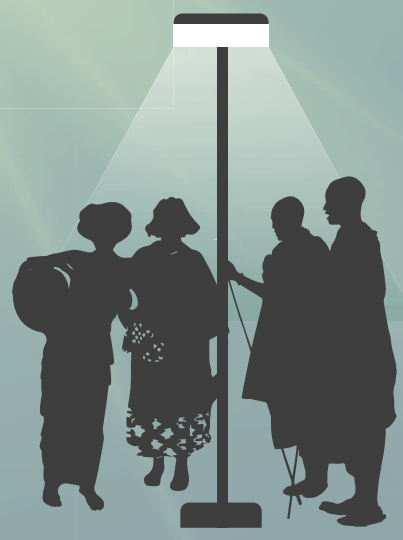

Community groups can help facilitate assessments, identify priority locations and households, test the lights, and train others on how to maximize efficiency and use all available functions.

'Community-based' means more than consultation and feedback - it requires actively and consistently working in partnership with camp residents.

Many refugees and IDPs have existing skills or could be trained to play a technical role in lighting projects.

\section{Community Lighting Groups can:}

- enable the active involvement of women, girls and other groups who may be socially marginalized;

- build community ownership of public lighting;

- deter anti-social behaviour, theft and vandalism;

- monitor performance of lights and quickly identify problems;

- carry out basic maintenance, such as cleaning solar panels, clearing vegetation and checking for the erosion of foundations;

- liaise with the community to identify problems (e.g. light pollution into shelters and repositioning suggestions);

- provide feedback on the impact of lighting and enable bilateral communication with the community. 


\section{THE LIGHTING LIFECYCLE}

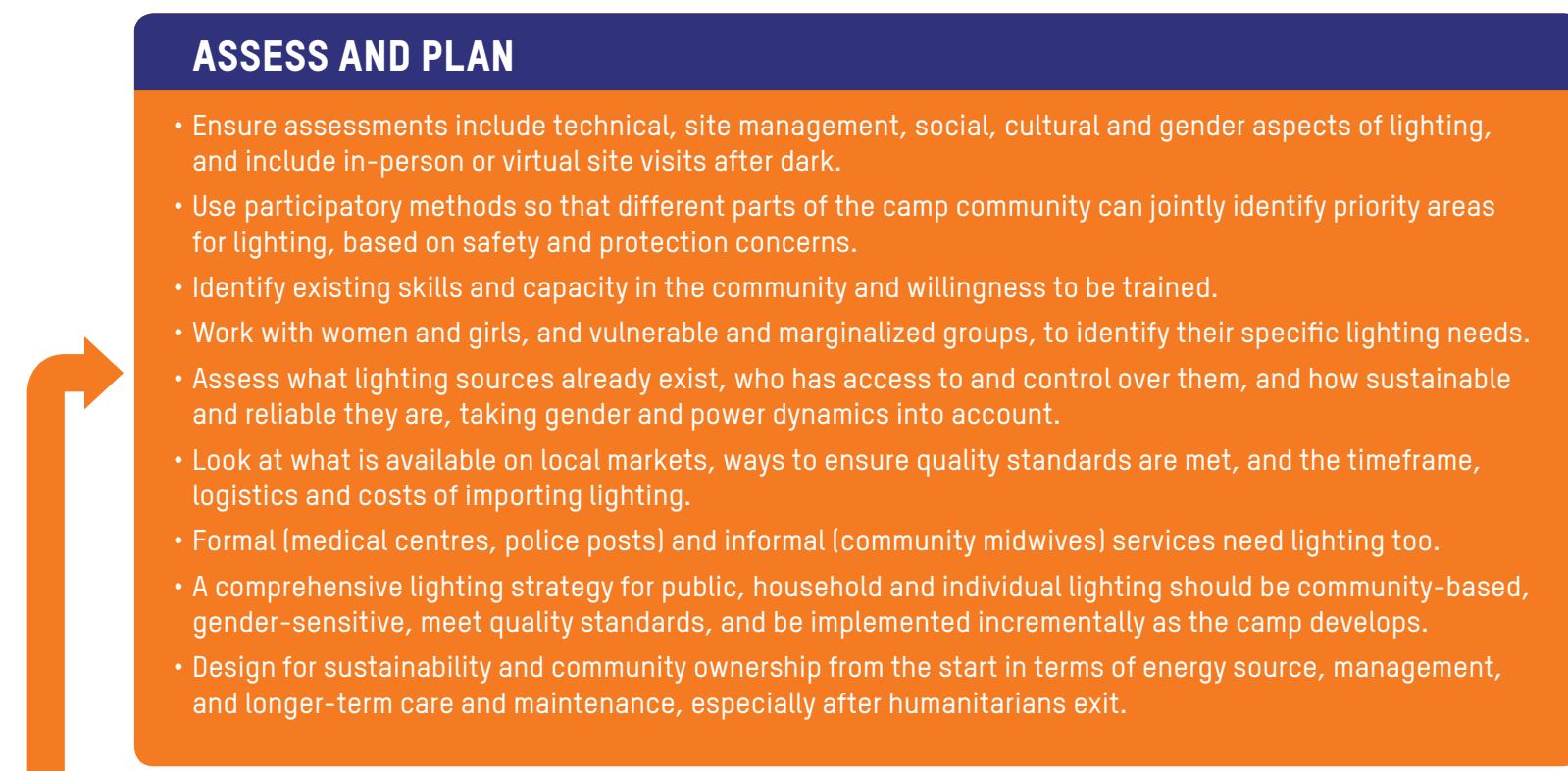

\section{IMPLEMENT AND MONITOR}

- All lighting actors should agree joint technical standards taking into account community-based approaches and issues such as weather-proofing, safety, and care and maintenance planning.

- Establish a coordination structure for all lighting actors and investigate options for joint purchasing.

- Work with communities to test and decide on models, durability, capital and running costs, warranties, user preferences such as portability, brightness, size/weight, and functions such as mobile phone charging.

- Consider household size and the needs/access of different individuals for different purposes, to determine quantity and specification of lighting devices to ensure everyone has access when needed.

- Train contractors installing lighting on safeguarding and PSEA (protection against sexual exploitation and abuse) requirements, and make compliance with these and the technical guidance a contractual obligation.

- Consider working with local traders and cooperatives to ensure that the host community benefits.

- When distributing household and individual lights, ensure that people know how to use all the functions, the most effective way to conserve battery power and how to activate the warranty.

- Train, resource and support groups who are maintaining and building community ownership of public lighting, and ensure they have approval and support from camp authorities.

- Maintenance groups can monitor and record performance issues with public lights, identify problems solutions and be a conduit for ongoing feedback.

\section{ADAPT, SUSTAIN AND LEARN}

- Have a repair and maintenance fund for public lighting - buy the main spare parts and tool kits in advance, and build skills in the community.

- Carry out regular checks and monitoring of all forms of lighting. Continue to support community maintenance groups beyond initial project funding.

- Make sure you know how to activate warranties and guarantees on lights and key parts of public lights, such as batteries and solar panels.

- Install public lighting in a way that reduces risks of theft and vandalism, but allows re-angling or repositioning at a later stage if required (e.g. if causing light pollution in homes).

- Document and share learning to increase humanitarians' knowledge and technical ability on lighting.

- Monitor and evaluate - consider peer reviews and evaluations with other agencies working on lighting, as well as participatory and community-based learning processes.

- Promote innovation, e.g. explore how public lighting can generate income, such as renting space underneath some lamp posts to traders, to fund longer-term maintenance and repairs. 


\section{EVERY CAMP IS DIFFERENT}

This research project looked specifically at camps for internally displaced people or refugees. No two camps are the same and it is impossible to make generalizations; however, what they do have in common is that they house people who have been forced to leave their homes to flee violence. Camps are places of refuge, but are also known to be places of potential danger and insecurity.

The three camps that featured in the field studies were very different from one another and evolved during the research period. The camp in Iraq was pre-planned and some elements of the population were transient, being temporarily housed before moving to another location or returning home. Aburi camp in Nigeria is not officially recognized by the authorities, although it does have infrastructure and leadership. It was striking that in both Nigeria and Iraq, people fleeing internal conflict were treated with some suspicion by authorities and military actors due to the risk of potential infiltration by armed actors, and this affected the sex balance as men and older boys were detained for security screening before arriving in the camps. In Uganda, the camp was planned and there was no military presence as the refugees were fleeing conflict over the border in South Sudan. The camp was managed by the Office of the Prime Minister, and civilian police including female police - were present on site. The case studies document some of the challenges that informal sites present: from the informal tented settlements for Syrian refugees in Lebanon's Bekaa Valley to the vast spontaneous camps for Rohingya refugees in Bangladesh.

All three camps where the field studies took place were relatively new. In fact, while we carried out research in Uganda, new refugees were arriving daily and aid actors were struggling to keep up. This was undoubtedly a contributing factor to the slow transition from communal to shared (less than five households) or household latrines. However, between baseline and endline people had got to know each other, and a sense of community was starting to develop. This is important, because in all research locations people expressed a fear of 'strangers', and not knowing those around them was certainly a factor in their perceptions of risk.

All camps change over time, not only in terms of social cohesion but also physical infrastructure. This is important for lighting, as it needs to be fixed in a way that allows for adaptation at a later stage. In Omugo, miscommunication and coordination difficulties meant that the lamp posts were installed at locations where tanks were filled by water trucking, even though this was due to change soon afterwards. Observations in older parts of Rhino settlement, where lamp posts had been in place for one to two years, found that while some had been well-sited, others had been badly positioned and angled such that they actually cast shadows over the precise areas that people had asked to be lit. As a result of these findings, the lamp posts documented in the one case study from Bangladesh were designed so that they could easily be removed from their concrete foundations and repositioned if required.

Perhaps the greatest learning point about camps is that anything that is done in them needs to be done in partnership with the people who reside there. They need to have a high level of ownership, and be able to bring their own skills, ideas and knowledge to humanitarian action if it is to meet their needs effectively and efficiently.

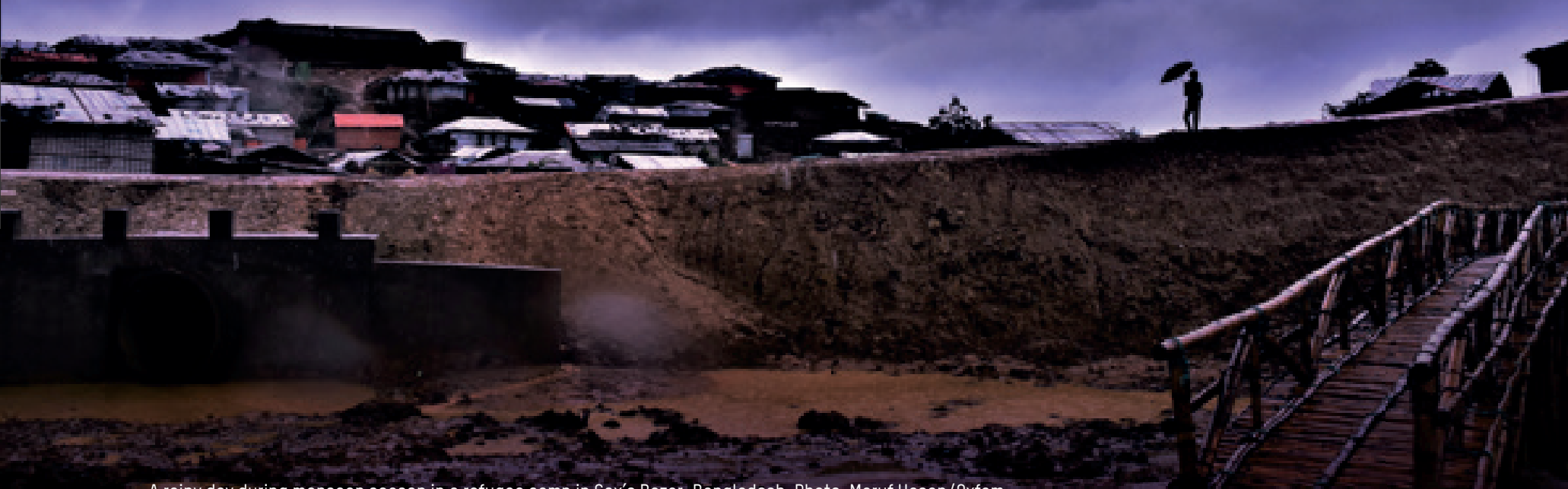




\section{CONCLUSIONS AND RECOMMENDATIONS}

The overall focus of the research was on whether lighting can reduce risks of GBV. Unsurprisingly, we have concluded that it takes more than lighting to reduce GBV risks. Since 2015, the IASC GBV Guidelines ${ }^{18}$ have provided guidance on lighting and GBV. They state that in camps, the setup of GBV risk-reduction activities should be undertaken, including 'adequate lighting in all public and communal areas deemed to be at high risk of GBV. Camp management should prioritize the installation of appropriate lighting.' Sphere and other standards also require 'adequate lighting'. There is no definition of what constitutes 'adequate lighting', and it is likely to be largely context-specific. What is clear, however, is that lighting will only ever be one part of a GBV reduction strategy, and that multiple other simultaneous, wellcoordinated actions are needed to effectively reduce risk.

Women and girls' fear of GBV is worryingly high in camps, especially in the initial stages when there is little sense of community and governance structures have not been fully established. Despite this, camp residents have strong ideas about what can be done to improve safety. Ongoing community engagement with all sub-sections of a camp population is critical to ensure good-quality humanitarian action, to uphold the dignity of those in crisis and to respect their agency and capacity to improve their own situation. This needs to go beyond 'listening' to include taking action and making changes in response to community feedback.
What our research does show is the surprisingly high extent to which communal latrines are not being used, both in the daytime and more so after dark, by women and men, and the reasons which link this to fears of GBV. Again and again, the factors interlink - a poor location with inadequate separation of facilities by sex combined with poor build quality and/or repair and maintenance leads women and girls to see sanitation facilities as risky places, especially after dark. None of these factors are unknown - they have all been recognized in the existing humanitarian quality standards. As humanitarians, we set these standards because we know it is important for people's needs to be met in safety, privacy and dignity. This research reinforces the existing knowledge, but the question we really need to ask is: why are we so consistently unable to meet these standards and what can we do immediately to start rectifying the problem? Lack of funding, capacity, resources and technical expertise clearly all play a part and must be urgently addressed.

There are specific areas that the research did not cover - children under 16 were not directly involved, although interviews with 16 to 19-year-olds showed that teenage girls have very high levels of fear of GBV, as do some teenage boys. Teenagers in FGDs in Uganda painted a very different picture of how they experience the camp environment compared to adults, and this may be a fruitful area for future research. Additionally, this research did not specifically look at issues for gender and sexual minorities, which is another critical gap in knowledge and evidence that needs attention.

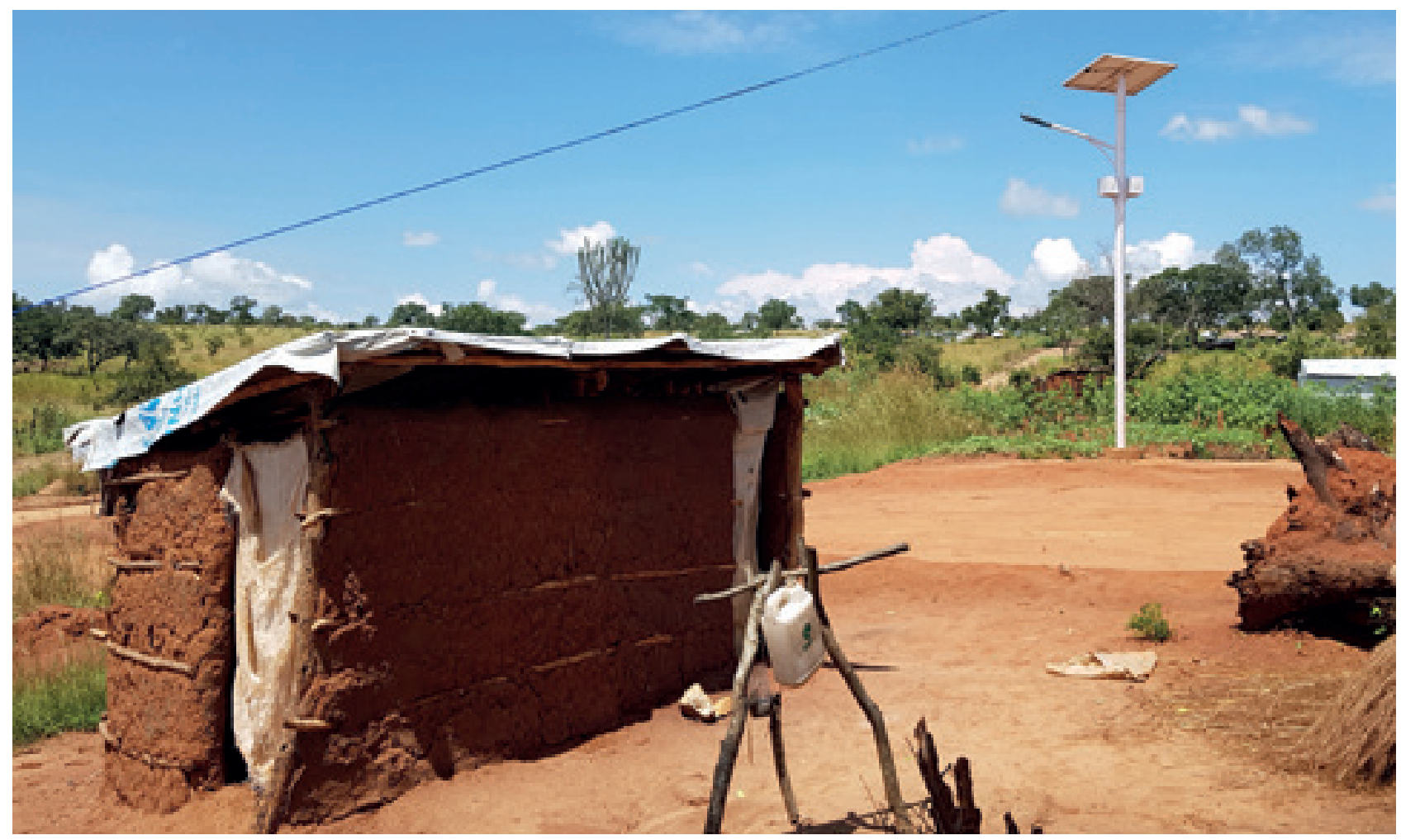

A latrine and light in a refugee camp in Uganda. Photo: Rachel Hastie/0xfam 
Lighting - at sanitation facilities or elsewhere - can improve feelings of safety, but alone will not reduce GBV. There are very high levels of fear of GBV in camps, especially among women and girls.
Reducing risks of GBV in camps requires a comprehensive gender-sensitive strategy that takes into consideration the physical environment, design and management of infrastructure, such as latrines, as well as the social and cultural factors and underlying inequalities that enable many forms of GBV. An effective strategy needs to be developed and implemented by all humanitarians and authorities together, with advice and support from GBV specialists. For this to happen, humanitarians have to break out of their sectoral 'silos' and start working together in a much more constructive and coordinated manner.

\section{People need multiple forms of good-quality lighting for it to be an effective safety measure.} Lighting has wider benefits such as enabling easier and cleaner use of sanitation facilities, avoiding snakes and scorpions, and also promotes community cohesion, family relationships and social and economic activity.

Access to and control of lighting is affected by gender and power dynamics. The most vulnerable people are at greater risk of being targeted for theft.
A strategic approach to camp lighting needs to combine lighting of public areas, services and facilities, and household and individual lighting, with an emphasis on consistency in quality, sustainability of energy source, and planning for longer-term maintenance.

Community-based approaches are essential to ensure that lighting meets the safety needs of the most vulnerable people, and is sustainable. The humanitarian sector needs a mechanism to coordinate how it meets lighting and other energy needs. It also needs to develop technical guidance to drive best practice, define standards and quality, and carry out joint research, reviews and evaluations to enhance learning.

Lighting initiatives need to be based on a strong understanding of gender relations and other power dynamics, or they will not benefit women and girls and the most vulnerable and marginalized people. Assessments and consultations need to include all groups, and ideally include a site visit after dark to find out what lighting exists already, who has access to and control over it, and how any new lighting inputs will be affected by gender and power dynamics. Humanitarians need to build up a stronger body of learning on lighting to inform operational guidance. Lighting - and all energy - interventions must take into account social, cultural and gender issues as well as 'hard' technical factors.

\begin{abstract}
Communal sanitation facilities (and the paths to and from them) are seen as places of potential danger for women and girls, especially where male and female facilities are not separated. Women and girls feel shame and embarrassment at being seen going to the latrine by men and boys. All these factors negatively affect usage rates.
\end{abstract}

All communal sanitation facilities should be separated and clearly identified as for male or female use. Designing sanitation facilities to allow for later adaptation, combined with ongoing community engagement, is critical for addressing safety issues and GBV risks in particular. Regular consultations should be held with women and girls, combined with monitoring of sanitation facilities and resources to make adaptations. Lighting can be designed to allow enough visibility while also protecting the privacy of users. Many women and girls would like female-only areas for combined latrines and bathing with good levels of privacy. Where GBV risks are high and people are using bags/buckets instead of sanitation facilities, humanitarians should support systems for the safe and dignified disposal of waste. A quicker transition from communal to shared or household sanitation facilities is essential for increasing women and girls' feelings of safety. This requires donors to allow flexibility, and those installing or contracting the installation of sanitation facilities to have adequate technical capacity, a strong relationship with the community, and flexible management structures.
The location, build quality (doors, walls, locks etc.) and condition of sanitation facilities have a significant impact on women and girls' fear of GBV, and this affects usage rates. Poor-quality sanitation facilities are putting women and girls at greatest risk of GBV.
The most immediate action that needs to be taken by humanitarians, donors and authorities to make women and girls safer in camps is to radically improve the quality of emergency sanitation - first and foremost by meeting existing standards outlined in Sphere and the IASC GBV Guidelines. Cost-cutting in construction and capacity for proactive community engagement puts women and girls at risk and reduces latrine usage - undermining the very public health goals that are the objective of providing emergency sanitation. Latrines and other sanitation facilities need to be of the highest standard possible, not the cheapest per unit, and they need ongoing community engagement with all sub-sectors of a community, not just an initial one-off consultation. Resources and capacity must be available to make necessary adaptations and adjustments based on community feedback. Humanitarians need to influence the training and ongoing professional development of public health engineers and other WASH specialists to ensure that they have the capacity and skills to meet standards, and managerial accountability is in place. 


\section{NOTES ON METHODOLOGY}

This research began with a comprehensive literature review of peer-reviewed literature, technical guidelines, grey literature, and interviews with key informants. Eight brief case studies of lighting interventions were also developed. The field research methodology was designed to collect data through a combination of quantitative data (a digital survey conducted with camp residents) and qualitative data (KIIs, research team observations within the camps, and FGDs with camp residents).

The field research aimed to meet high ethical standards including best practices for data collection on GBVrelated issues as defined by the IASC: not probing too deeply into culturally sensitive or taboo topics; not singling out GBV survivors for interviews; and not speaking to women and girls directly about their own experiences without the presence of GBV specialists. This was particularly important in these contexts, given the limited options for GBV referral services and security concerns for GBV survivors. The digital survey therefore asked questions which included four key indicators to measure the 'perception of risk of GBV' and 'fear of GBV', as outlined on page 10. The FGDs included contextspecific scenarios to allow discussion of sensitive personal, cultural or GBV-related issues through a third-person situation. These scenarios proved very effective for generating discussion and debate, and for increasing understanding and contextualizing some aspects of the survey data while enabling participants to talk about sensitive issues in a depersonalized manner.

The research team aimed to survey a representative sample of the adult camp population using existing demographic data to establish results to a Confidence Interval of 5 and Confidence Level of $95 \%$ to the extent possible, given challenges in all field locations. Where possible, survey enumerators targeted people proportionally based on sex, age and disability. Children under 16 were not interviewed as Oxfam did not have the adequate mechanisms to ensure their consent, safety and wellbeing. While we did not actively seek them out, teenagers aged 16-19 were included, with additional safeguards in place.
Field enumerators underwent training on methodology and safeguarding in each location. The training also integrated an assessment to identify and mitigate potential risks for the research team and participants, such as disclosures of GBV incidents, eavesdropping during interviews, and encountering snakes and scorpions. Although the research initially intended to include safety issues for sexual and gender minorities, risk assessments indicated that it would be difficult to do so ethically and safely, given the heightened sensitivities in these specific locations and the absence of LGBTIQ response actors.

Any kind of community-based research, especially in conflict situations, can lead to people disclosing details of incidents or abuse that they or others have suffered, sometimes requiring immediate response. In anticipation of this, the researchers were accompanied by Oxfam's Protection Teams who are prepared to deal with such situations and know the GBV referral process in place.

Where possible, following a rapid analysis of trends in the survey data, the structure of FGDs was developed to probe and enhance understanding of specific issues. For example, in Uganda a high number of female respondents identified 'being seen' as a risk that prevented them using the sanitation facilities. To better understand this, a scenario was used in all the FGDs: 'Sarah is worried about being seen going to the latrines. Why do you think that is? What is she worried about? Is she right to be worried?

There were numerous limitations to the research, many relating to the challenges of working in complex, insecure contexts. They include issues related to translation, experience of enumerators, and to the sequencing of the digital surveys, FGDs and KIIs. Some limitations were also linked to the repetitive nature of the survey that asked respondents to rate risks going to the sanitation facilities first during the day, then after dark, and while using the sanitation facilities during the day, and then after dark, which meant that enumerators needed time to explain each of the different concepts. Time variations in some of the data-entry logs suggest that enumerators sped up as they progressed. This may have been the result of enumerators becoming more familiar with the surveys, though it could suggest that the time may not always have been taken to fully explain concepts, which may have affected the quality of data collected.

The detailed methodology and tools are available upon request, and an adapted version will be available in 2019 . 


\section{NOTES}

1 The literature review, country reports, and eight case studies can be found here: https://policy-practice.oxfam.org.uk/our-work/ humanitarian/sanitation-lighting

2 The endline research took place after three to eight months, depending on location.

3 HIF (2015). Call for Proposals - Research on Latrine Lighting in Emergency Context: Testing Lighting Innovations. http://www.elrha. org/wp-content/uploads/2015/03/ToR-Research-on-LatrineLighting-in-Emergency-Context.pdf

4 The literature review, country reports, and eight case studies can be found here: https://policy-practice.oxfam.org.uk/our-work/ humanitarian/sanitation-lighting

5 FGD with adult female IDPs, Nigeria

6 FGD for women, tank 14, Uganda

7 FGD with adolescent girls, Iraq

8 KII with Non-violent Peaceforce, Iraq

9 KII with INTERSOS referrals team and psychosocial support caseworkers, Iraq

10 FGD male community mobilizers (aged 18-50), Iraq

11 KII with Oxfam Protection Team in Nigeria

12 Oxfam GBV and lighting assessment, Damboa, Nigeria

13 KII with ECHO in Iraq

14 KII with GBV sub-group

15 FGD with young women aged $20-30$ years, Nigeria

16 FGD with adolescent boys, Nigeria

17 KII with Office of the Prime Minister, Arua, Uganda

18 IASC (2015). Guidelines for Integrating Gender-Based Violence Interventions in Humanitarian Action. https://gbvguidelines.org/wp/wp-content/uploads/2015/09/2015IASC-Gender-based-Violence-Guidelines_lo-res.pdf

The Oxfam WASH team has also developed a series of communications tools to promote best practices in sanitation, and to provide guidance for the sector more widely. See www.oxfam.org.uk/sanitweaks

Front cover photo:

A Rohingya refugee with a solar powered lamp in Cox's Bazaar, Bangladesh. Photo: Abbie Trayler-Smith/Oxfam

Back cover photo:

A woman walks through a refugee camp in Iraq.

Photo: Sam Tarling/Oxfam

\section{ACKNOWLEDGEMENTS}

This research was carried out with the involvement and support of a large group of people. We would like to thank the residents of Aburi, Hamman Al Alil 2 and Omugo camps for giving their time and sharing their experiences; and the Oxfam teams and other humanitarian actors and authorities in Nigeria, Iraq and Uganda. The research team included Brian Reed, Jeanne Vidal and Dr Julie Fisher at WEDC; and Kerry Akers, Rachel Hastie, Julie Lafreniere, Corrie Sissons and Marion O'Reilly with support from Andy Bastable, Jack Wilkins and Tanya Glanville-Wallis at Oxfam. We would also like to thank colleagues at CARE, UNHCR, DFID, IOM, Little Sun and the GBV Guidelines Inter-Agency Reference Group for their input, and the Humanitarian Innovation Fund who set the challenge, provided ongoing support and funded the research.

\section{(C) Oxfam International and WEDC December 2018}

This publication is copyright but the text may be used free of charge for the purposes of advocacy, campaigning, education, and research, provided that the source is acknowledged in full. The copyright holder requests that all such use be registered with them for impact assessment purposes. For copying in any other circumstances, or for re-use in other publications, or for translation or adaptation, permission must be secured and a fee may be charged. Email policyandpractice@oxfam.org.uk. The information in this publication is correct at the time of going to press.

For further information on the issues raised in this paper please email rachel.hastie@oxfam.org

Published by Oxfam GB for Oxfam International and WEDC under ISBN 978-1-78748-355-2 in December 2018. Oxfam GB, Oxfam House, John Smith Drive, Cowley, Oxford, 0X4 2JY, UK. DOI: 10.21201/2018.3552.

Oxfam is an international confederation of 19 organizations networked together in more than 90 countries, as part of a global movement for change, to build a future free from the injustice of poverty. Please write to any of the agencies for further information, or visit www.oxfam.org.

\section{WEDC at Loughborough University}

The Water, Engineering and Development Centre (WEDC) is one of the world's leading education and research institutes for developing knowledge and capacity in water and sanitation for sustainable development and emergency relief. It is committed to the provision of effective, evidence-based and appropriate solutions for the improvement of basic infrastructure and services for people living in low- and middle-income countries. For more information, please contact wedc@lboro.ac.uk

\section{Elrha's Humanitarian Innovation Fund}

The project this paper is part of is supported by Elrha's Humanitarian Innovation Fund programme, a grant making facility supporting organisations and individuals to identify, nurture and share innovative and scalable solutions to the most pressing challenges facing effective humanitarian assistance. The HIF is funded by aid from the UK Government.

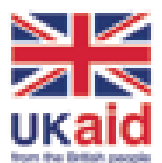

Visit www.elrha.org for more information about Elrha's work to improve humanitarian outcomes through research, innovation and partnership. 


\section{LAST WORDS}

'It's great to see organizations focusing on the critical need for women and girls to have safe access to WASH facilities. This research demonstrates the importance of putting the safety of women and girls at the heart of humanitarian assistance.'

Erin Patrick, GBV Guidelines Inter-Agency Reference Group
'Lighting clearly makes people feel safer; as humanitarians we need to use the findings of this research and be innovative about how we work with people in camps to ensure everyone gets equal access to good quality and sustainable lighting.'

Rachel Hastie, Protection Adviser, Oxfam

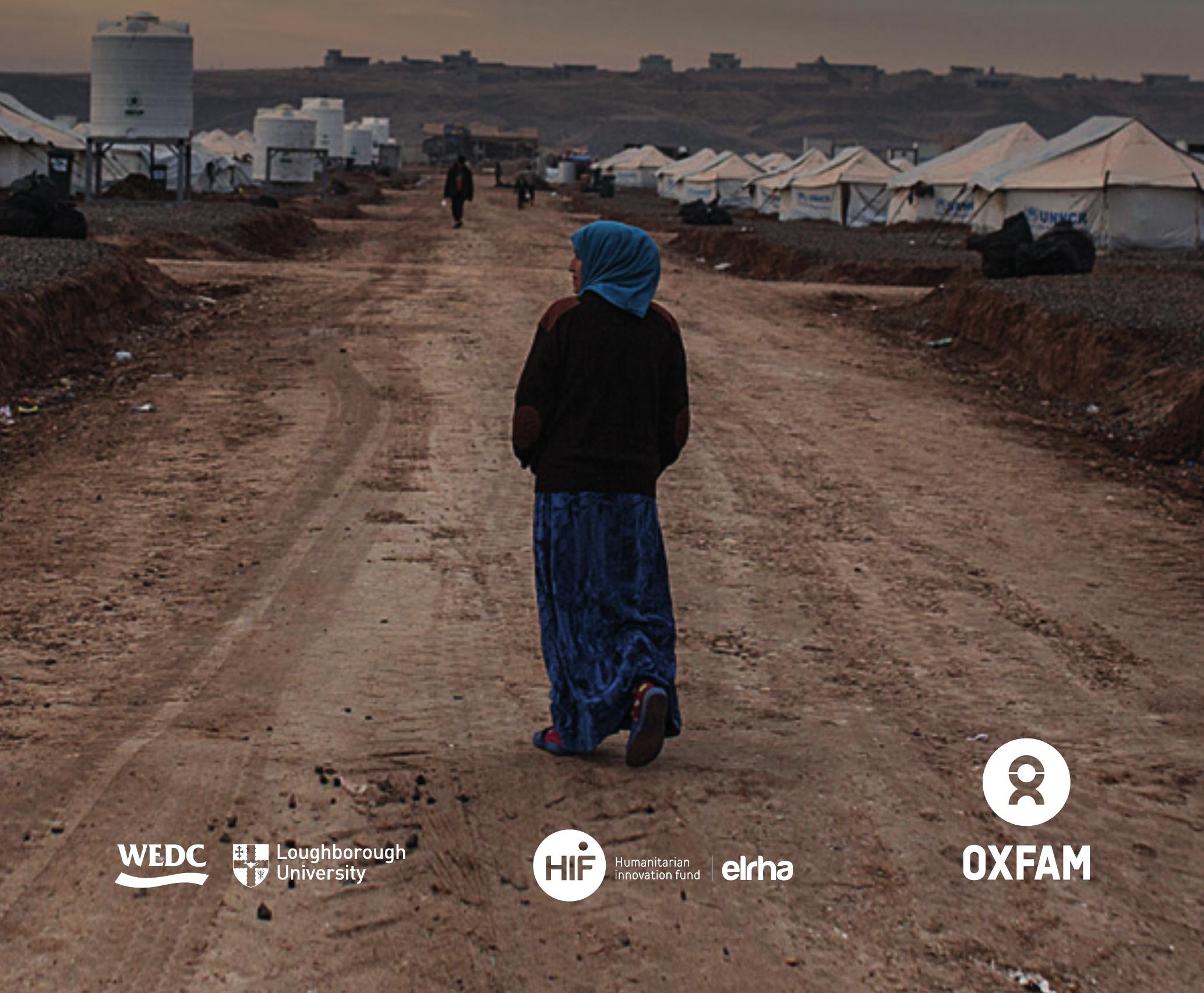

